\title{
Optimizing the Early Diagnosis of oral Muccosal Pathologies
}

\author{
DOI: 10.17691/stm2017.9.3.16
}

Received January 26, 2017

O.V. Shkarednaya, MD, PhD, Tutor, Department of Dentistry, Faculty of Doctors' Advanced Training;

T.P. Goryacheva, PhD Student, Department of Dentistry, Faculty of Doctors Advanced Training ${ }^{1:}$

A.A. Chunikhin, MD, PhD, Associate Professor, Department of Oral Surgery2;

E.A. Bazikyan, MD, DSc, Professor, Head of the Department of Oral Surgery2;

S.I. Gazhva, MD, DSc, Professor, Head of the Department of Dentistry, Faculty of Doctors Advanced Training 1

${ }^{1}$ Nizhny Novgorod State Medical Academy, 10/1 Minin and Pozharsky Square, Nizhny Novgorod, 603005,

Russian Federation;

${ }^{2}$ Moscow State University of Medicine and Dentistry named after A.I. Evdokimov, 20/1 Delegatskaya St., Moscow, 127473, Russian Federation

The aim of the investigation was to improve the algorithm for early diagnosis of pathological and malignant processes in the oral mucosa and detection of their true boundaries by involving the method of direct tissue autofluorescence visualization in this algorithm.

Materials and Methods. A prospective randomized clinical study was carried out. Its results provided the possibility to improve the algorithm for oral mucosa examination. The scheme of topography and coding elements of lesion of the lips mucous membrane taking into account the zone of localization of the pathological process. The limits of possibilities of direct tissue autofluorescence visualization method in verification of various oral mucosal lesions were evaluated.

Results. The proposed algorithm for examining the patients with pathological changes of the oral mucosa includes visual examination of the oral cavity and detection of pathological processes, topography and coding the mucous membrane elements, visualization and analysis of polymorphism of mucosal epithelial cells using direct tissue autofluorescence visualization method and biopsy material microscopy.

Key words: oral cavity; pre-cancer; cancer; early diagnosis; direct tissue autofluorescence visualization.

The results of the latest national epidemiological dental survey show that oral mucosal diseases are increasingly common among the young people, leading to worsening and chronicity of the process in adult population and in some cases to malignancy $[1,2]$.

According to the WHO data, the mortality from oncological diseases ranks second after cardiovascular pathology [3]. In 2015, the mortality rate from malignant tumors in Russia equaled nearly 300,000 people [1].

If the process is located in the head and neck area, every third cancer patient dies within a year after the diagnosis, and the survival threshold for people with this pathology is no more than 5 years $[3,4]$. One of the reasons for a late visit to the doctor is blurred clinical picture at the initial stages of the disease. Despite the simplicity of clinical visualization of oral mucosal changes, diagnosing nosological forms of precancer based only on the results of clinical examination and palpation often leads to diagnostic errors because the varying degrees of keratinization or ulceration of lesion elements make them difficult to differentiate [5].

Early diagnosis of malignancy is especially difficult because clinical signs appear much later than malignant transformation actually occurs. The percentage of incurable forms of oral mucosal cancer due to diagnostic errors reaches $58.4-70 \%$, according to different authors $[4,5]$.

The problem of early diagnosing of the oral mucosal abnormalities is not only relevant, but vitally important and socially significant, requiring implementation of modern screening technology in order to be solved.

The lack of methodological approach and clear algorithm for early diagnosis of morphological signs of oral mucosal diseases is the basis for studying the problem.

The aim of the investigation was to improve the algorithm for early diagnosis of pathological and malignant processes in the oral mucosa and to detect their true boundaries by applying the method of direct tissue autofluorescence visualization in this algorithm.

Materials and Methods. A total of 80 patients of both genders aged 20 to 60 years underwent oncological screening of the oral mucosa. The patients were divided into two groups based on the clinical condition of the mucous membrane, which was determined by the presence or absence of visible abnormalities: group 1 comprised 40 patients with clinical manifestations of pathological processes in the oral mucosa; group 2 (control) consisted of 40 healthy individuals with no visible changes in the mucosa and no concomitant

For contacts: Shkarednaya Olga V., e-mail: stomfpkv@mail.ru 
Table 1

\section{Distribution of patients in groups under study}

\begin{tabular}{clcc}
\hline $\begin{array}{c}\text { Groups } \\
\text { under study }\end{array}$ & \multicolumn{1}{c}{ Clinical diagnosis } & ICD-10 & $\begin{array}{c}\text { Number } \\
\text { of patients }\end{array}$ \\
\hline & Lichen planus & L43 & 10 \\
\cline { 2 - 4 } & Leukoplakia & K13.2 & 5 \\
\cline { 2 - 4 } Group 1 & $\begin{array}{l}\text { Chronic recurrent aphthous } \\
\text { stomatitis }\end{array}$ & K14.0 & 7 \\
\cline { 2 - 4 } & Decubital ulcer & L89 & 5 \\
\cline { 2 - 4 } & Cancer & C00-C07 & 1 \\
\cline { 2 - 4 } & Herpetic stomatitis & B00.2 & 7 \\
\cline { 2 - 4 } & Desquamative glossitis & K14.1 & 5 \\
\hline \multirow{2}{*}{ Group 2 (control) } & Normal oral mucosa & - & 40 \\
\hline
\end{tabular}

somatic pathology, according to the conclusion of the therapist (Table 1).

The work was based on the principles of evidencebased medicine. All patients under study were standardized by gender, age groups and nosological forms. The study complies with the Declaration of Helsinki (the Declaration was passed in June 1964, Helsinki, Finland, and revised in October 2000, Edinburgh, Scotland) and was performed following approval by the Ethic Committee of Nizhny Novgorod State Medical Academy. Written informed consent was obtained from every patient.
To evaluate the diagnostic potential of direct tissue autofluorescence visualization method, there was performed an examination based on the ability of the affected tissue to accumulate specific photosensitizer or induce the formation of endogenous porphyrins and registering their fluorescence under exposure to light irradiation at a specific wavelength. In this examination, autofluorescence of healthy tissues is observed in the green part of the spectrum, while a sharp decrease in autofluorescence intensity is registered in the area of malignant process development compared to the surrounding healthy tissue. This effect is called "dark spots" due to the fact that the epithelium of premalignant and malignant lesions emits fluorescence of lower intensity than the epithelium of healthy mucosa.

The examination was carried out with the aid of the VELscope Vx system (WhiteRock, Canada). The system operates using light flux of a certain spectrum to detect structurally altered tissue. When the oral mucosa is exposed to light of wavelength 400 to $460 \mathrm{~nm}$, excitation of green-red fluorescence of endogenous fluorophores occurs in the mucosal tissue. The tissue fluorescence is viewed directly along the optical axis collinear with the excitation axis. Normal mucosa emits various shades of green autofluorescence (Figure 1). In case of pathological changes, fluorescence quenching is observed and a dark spot is visualized against the background of the surrounding tissue (Figure 2). Thus, the sites of normal bright green fluorescence loss are interpreted as foci requiring further investigation and
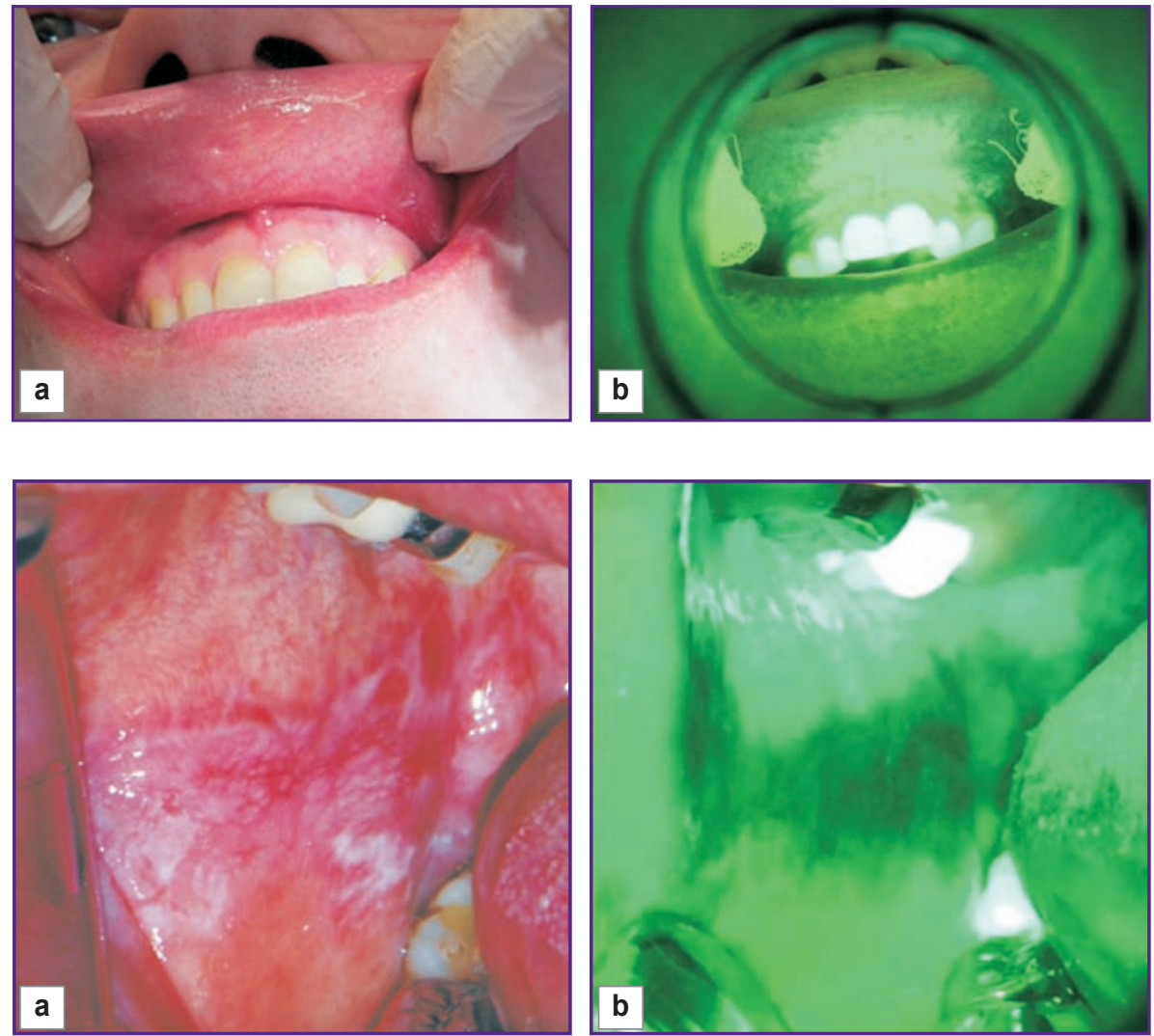

Figure 1. Normal oral mucosa:

(a) in artificial daylight; (b) bright green fluorescence in the light of the VELscope $V x$ device
Figure 2. Lichen planus, exudativehyperemic form:

(a) visualization on clinical examination in artificial daylight; (b) in the light of the VELscope Vx device 
evaluation and also as zones of pathological process localization $[6,7]$.

Observance of direct tissue visualization technique is an important issue. This technique should be carried out in a darkened room, with the device tube positioned at $20 \mathrm{~cm}$ from the oral mucosa. Special attention is paid to clinically unchanged areas of the mucous membrane with fluorescence quenching.

According to the WHO recommendations, visual examination of the oral cavity and detection of pathological processes in the mucosa were carried out based on 4-level diagnosis system. Topography and coding the elements of the oral mucosa was performed, according to Roed-Petersen and Renstrup (1969) in the modification by Gileva et al. (2008): buccal mucosa 19, 20 TC WHO (TC - topographic code); tongue 39-47 TC WHO; alveolar process - 27-38 TC WHO; vermilion border 13, $14 \mathrm{TC}$ WHO. To make the affected areas of the labial mucous membrane more specific, at the Department of Dentistry of Nizhny Novgorod State Medical Academy there was developed and implemented in dentistry practice the scheme comprising eight segments referenced by numbers from I to VIII and codes for the morphological elements of the lesion (the first letter of its Latin name): macula - code "M", papula code "P", nodus - code "N", tuberculum - code "T", ulcus — "U", rhagades — code "Rh", squama — code "Sq", crusta - code "C", erosion — code "E" [8].

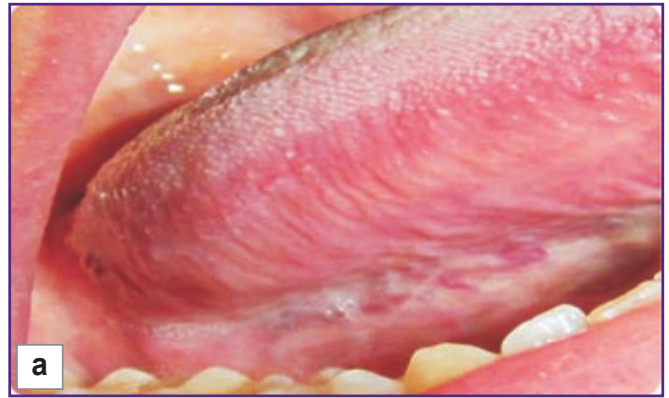

Figure 3. Normal oral mucosa:

(a) absence of pathology on clinical examination in artificial daylight; (b) dysplasia visible in the light of the VELscope $V x$ device (arrows)

Figure 4. Papilloma on the lateral surface of the tongue:

(a) visualization on clinical examination in artificial daylight; (b) in the light of the VELscope $V x$ device (arrow)
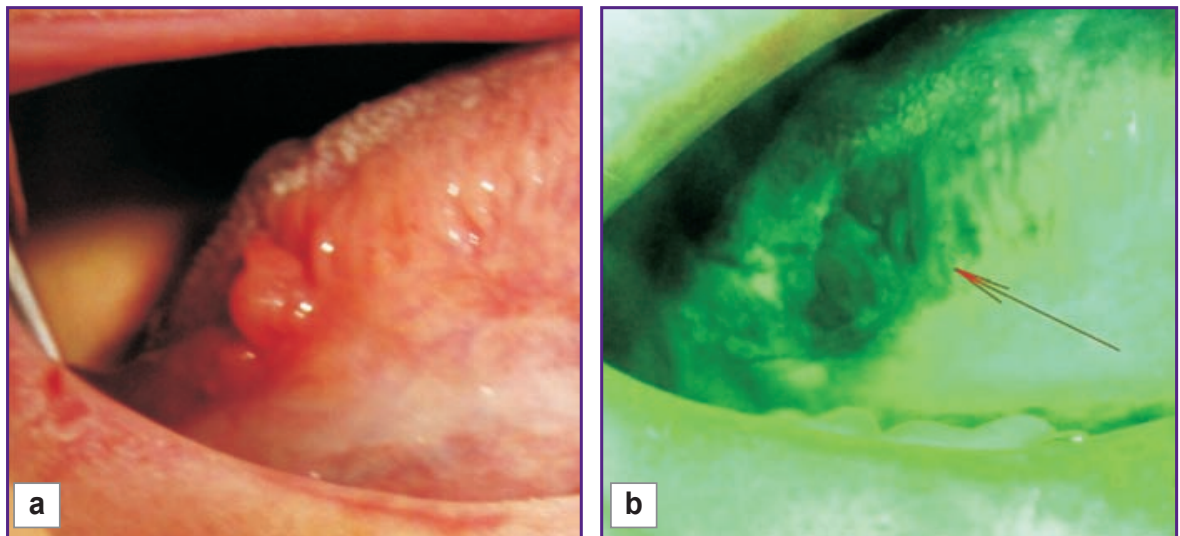

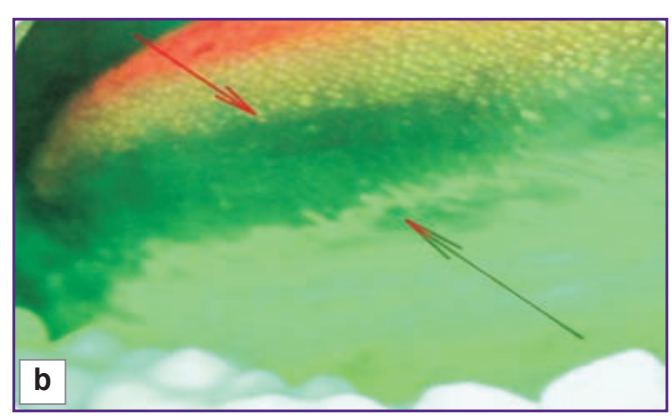

To compare the areas of oral mucosal lesions evaluated by visual examination and using the VELscope $V x$ device, we registered the dimensions (longitudinal and transverse) of pathological elements with a measuring compass. The areas of oral mucosal lesions were calculated by the formula [9]:

$$
S=\frac{a \cdot b}{4} \cdot \pi
$$

where $a$ is the longitudinal dimension, $b$ is the transverse dimension.

Results and Discussion. To determine the necessity for including direct tissue autofluorescence visualization method in the diagnostic algorithm, the Velscope $\mathrm{Vx}$ device was used in all 80 patients. Loss of fluorescence was observed in 44 cases $(55 \%)$ : change in normal bright green glow of the oral mucosa was observed in all individuals of group 1 and in 4 cases in group 2, whereas in 36 cases $(45 \%)$ in the control group, no deviation from normal optical images was found. Thus, in 4 patients of group 2 (healthy individuals) fluorescence loss was detected in the absence of clinical changes (Figure 3).

Complete fluorescence loss in the region of problem site was revealed in 40 patients of group 1 with obvious pathology in more than $75 \%$ of cases $(n=30)$, the loss was partial in 10 cases (Figure 4). Some images had a mixed result: alternating areas of fluorescence 

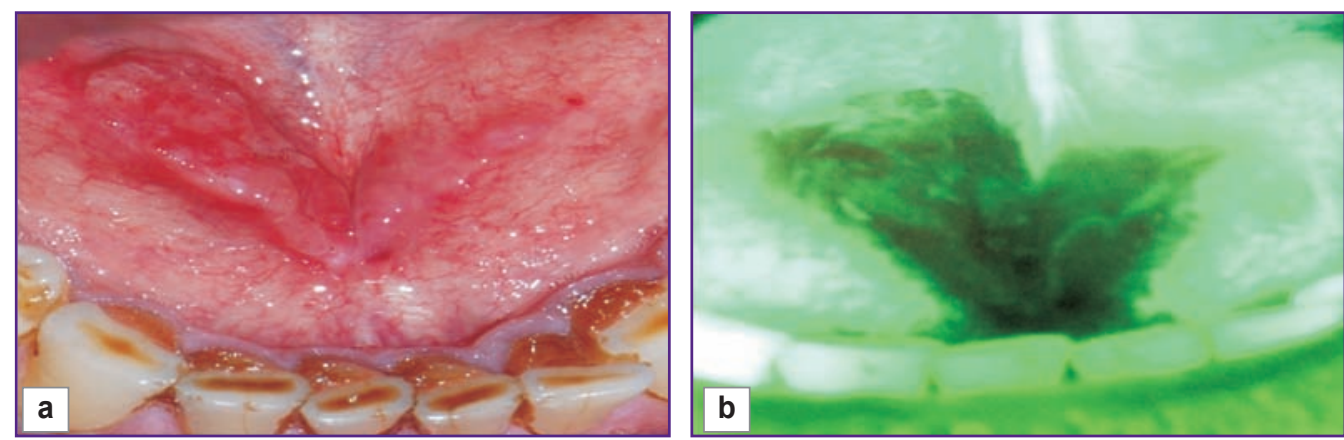

Figure 5. Non-keratinizing squamous cell carcinoma with signs of infiltrative growth of the oral floor:

(a) visualization on clinical examination in artificial daylight; (b) in the light of the VELscope Vx device

Table 2

The average area of pathological elements in patients with oral mucosal diseases when lesions are visualized by different methods

\begin{tabular}{|c|c|c|c|c|}
\hline \multirow{3}{*}{ Oral mucosal diseases } & \multicolumn{4}{|c|}{ The average area of pathological elements $\left(\mathrm{cm}^{2}\right)$} \\
\hline & \multicolumn{2}{|c|}{ Visual examination } & \multicolumn{2}{|c|}{ Using the VELscope Vx device } \\
\hline & $M \pm m$ & $M \pm \sigma$ & $M \pm m$ & $M \pm \sigma$ \\
\hline Lichen planus & $2.75 \pm 0.78$ & $2.75 \pm 1.57$ & $3.10 \pm 0.41^{*}$ & $3.10 \pm 1.24^{*}$ \\
\hline Leukoplakia & $2.33 \pm 0.94$ & $2.33 \pm 1.63$ & $2.75 \pm 0.66^{*}$ & $2.75 \pm 1.62 *$ \\
\hline $\begin{array}{l}\text { Chronic recurrent aphthous } \\
\text { stomatitis }\end{array}$ & $0.33 \pm 0.026$ & $0.33 \pm 0.064$ & $0.39 \pm 0.024^{*}$ & $0.39 \pm 0.076^{*}$ \\
\hline Decubital ulcer & \multicolumn{2}{|c|}{0.46} & $0.92 \pm 0.09$ & $0.92 \pm 0.24$ \\
\hline Cancer & $2.42 \pm 0.33$ & $2.42 \pm 1.05$ & $4.06 \pm 0.77^{*}$ & $4.06 \pm 2.77^{*}$ \\
\hline Herpetic stomatitis & \multicolumn{2}{|c|}{0.3} & $0.9 \pm 0.31$ & $0.9 \pm 0.54$ \\
\hline Desquamative glossitis & $1.28 \pm 0.28$ & $1.28 \pm 0.49$ & $2.28 \pm 0.66^{*}$ & $2.28 \pm 1.32^{*}$ \\
\hline
\end{tabular}

* Statistically significant difference between the values and visual examination data, $p<0.05$.

quenching and increasing in different areas of the affected site $(2.4 \%)$.

The area of fluorescence loss was significantly higher than the lesion area viewed with the naked eye in 21 cases (48\%) (Figure 5).

Thus, the area of pathological elements was calculated for each of the 40 patients with the oral mucosal diseases: when visualizing with the naked eye during clinical dental examination and with the VELscope $V x$ device. Table 2 shows the values of the average area of lesion elements for a specific nosological form of mucosal abnormality.

When analyzing the obtained data, we found that the examined patients had statistically significant difference $(p<0.05)$ in the average area of lesion elements on the oral mucosa visualized clinically and by using the VELscope $V x$ device. Thus, the method of direct tissue autofluorescence visualization provides a non-invasive means to determine true boundaries of the pathological process, which is important when choosing treatment strategy and evaluating its efficacy. Besides, the complex use of visual oral mucosal examination and direct tissue autofluorescence visualization method allows identifying the areas of risk for pathology occurrence, including precancerous conditions and cancer pathology (Table 3, Figure 6).

The results of the study showed that during the examination of the patient's oral mucosa, the dentist should pay particular attention to the areas of potential risk: the buccal mucosa, tongue, oral floor and retromolar areas.

However, it should be understood that the method of direct tissue autofluorescence visualization cannot serve as the basis for the final diagnosis, since only in vivo pathomorphological study of biopsy material from the affected areas has been the recognized gold standard for diagnosis. When detection of cancer process is suspected, it is absolutely necessary to perform biopsy.

All the results obtained in our study and indicating the presence of both explicit and latent pathology of oral mucosal epithelium were confirmed morphologically by studying biopsy samples taken from problem sites. Most of the diagnosed lesions were benign.

Analysis of the data obtained as a result of performing 
Table 3

Coding and topography of pathological processes in the oral mucosa

\begin{tabular}{|c|c|c|c|c|c|c|c|c|}
\hline \multirow[b]{2}{*}{ Lesion area } & \multicolumn{8}{|c|}{ Pathology } \\
\hline & $\begin{array}{l}\text { WHO } \\
\text { topographic } \\
\text { code }\end{array}$ & $\begin{array}{l}\text { Lichen } \\
\text { planus }\end{array}$ & Leukoplakia & $\begin{array}{c}\text { Chronic } \\
\text { recurrent aphthous } \\
\text { stomatitis }\end{array}$ & $\begin{array}{l}\text { Decubital } \\
\text { ulcer }\end{array}$ & Cancer & $\begin{array}{c}\text { Herpetic } \\
\text { stomatitis }\end{array}$ & $\begin{array}{c}\text { Desquamative } \\
\text { glossitis }\end{array}$ \\
\hline \multirow{2}{*}{ Buccal mucosa } & 19 & 5 & 2 & 3 & 1 & & & \\
\hline & 20 & 4 & & 2 & & & & \\
\hline \multirow{9}{*}{ Tongue } & 39 & 1 & & & & & & 2 \\
\hline & 40 & 1 & & 1 & & & & 2 \\
\hline & 41 & & & 1 & & & & \\
\hline & 42 & & & & & & & \\
\hline & 43 & 1 & & & & & & \\
\hline & 44 & 1 & 1 & & 1 & 1 & & 1 \\
\hline & 45 & 1 & 1 & & 1 & & & \\
\hline & 46 & 1 & 1 & 1 & & & & \\
\hline & 47 & 1 & 1 & 1 & & & & \\
\hline \multirow{12}{*}{ Alveolar process } & 27 & & & 1 & & & & \\
\hline & 28 & & 1 & & & & & \\
\hline & 29 & 1 & 1 & & 1 & & & \\
\hline & 30 & 1 & 1 & 1 & 1 & & & \\
\hline & 31 & 1 & & & & & & \\
\hline & 32 & & & 2 & & & & \\
\hline & 33 & & & & & & 2 & \\
\hline & 34 & & & & & & 3 & \\
\hline & 35 & & & 1 & & & & \\
\hline & 36 & & & 1 & & & & \\
\hline & 37 & & & & & & 2 & \\
\hline & 38 & & & & & & & \\
\hline \multirow{2}{*}{ Vermilion border } & 13 & 1 & & 1 & & & 3 & \\
\hline & 14 & & & & & & 2 & \\
\hline
\end{tabular}

the whole set of presented studies allowed us to improve the existing algorithm for examination of patients for early diagnosis of precancerous and malignant changes in the oral mucosa. This algorithm shall include the following diagnostic procedures:

1) visual examination of the oral cavity and detection of pathological processes in the mucosa;

2) topography and coding the affected mucosal elements;

3) visualization and analysis of polymorphism of oral mucosal epithelial cells using direct tissue autofluorescence visualization method;

4) microscopy of biopsy material.

Conclusion. For timely and reliable detection of potentially dangerous (precancerous or cancerous) lesions of the oral mucosa, it is required to perform a set of examination procedures. The proposed algorithm for early diagnosis of such lesions will facilitate optimization and efficacy of further treatment.

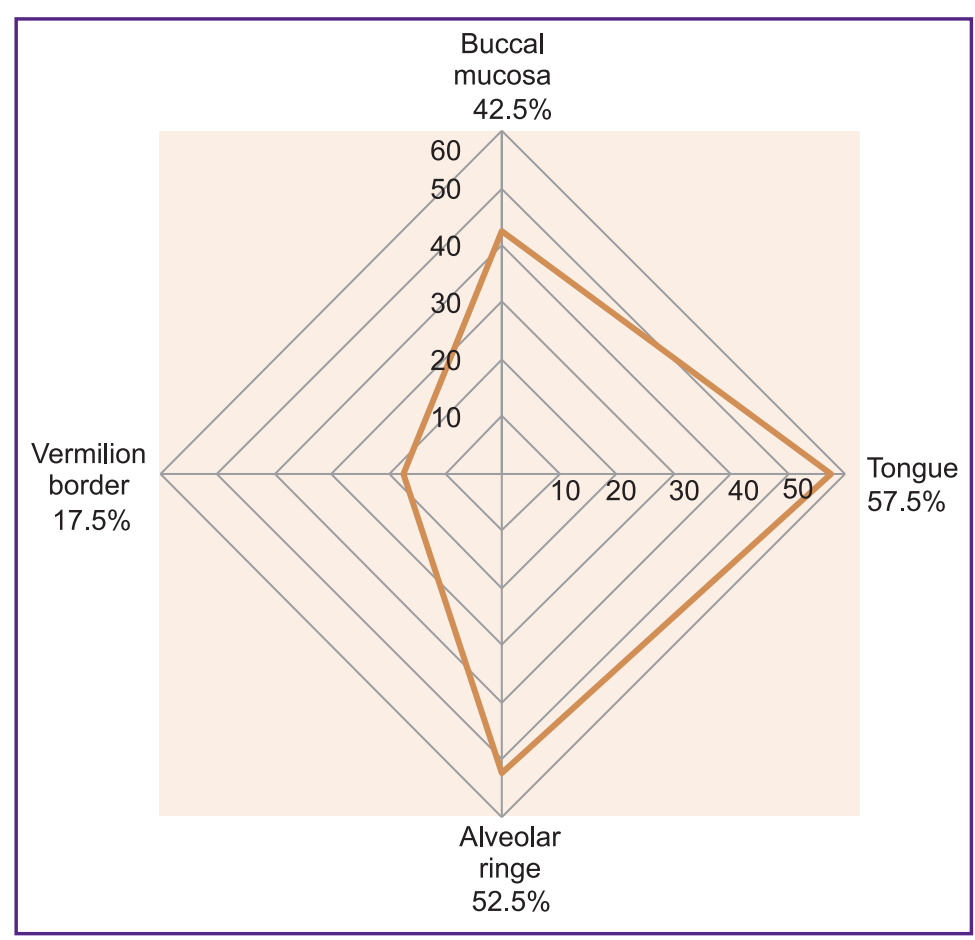

Figure 6. Localization of pathological processes in the oral mucosa 
Study Funding and Conflict of Interests. This study was not supported by any financial sources and the authors have no conflict of interests to disclose.

\section{References}

1. Zlokachestvennye novoobrazovaniya v Rossii v 2015 godu (zabolevaemost' i smertnost') [Malignant neoplasms in Russia in 2015 (morbidity and mortality)]. Pod red. Kaprina A.D., Starinskogo V.V., Petrovoy G.V. [Kaprin A.D., Starinskiy V.V., Petrova G.V. (editors)]. Moscow: MNIOI im. P.A. Gertsena - filial FGBU "NMIRTs" Minzdrava Rossii, 2017; 250 p.

2. Gazhva S.I., Grekhov A.V., Goryacheva T.P., Senina-Volzhskaya I.V. Problem of early diagnosis of oral oncopathology (social aspects). Sovremennye problemy nauki $i$ obrazovaniya 2015; 3. URL: http://science-education.ru/ru/article/ view?id=19168.

3. American Cancer Society. Cancer Facts \& Figures 2013. URL: https://assets.documentcloud.org/documents/ 1109107/acs-facts-and-figures-2013.pdf.

4. Mehrotra R., Gupta D.K. Exciting new advances in oral cancer diagnosis: avenues to early detection. Head Neck Oncol 2011; 3: 33, https://doi.org/10.1186/1758-3284-3-33.

5. Gileva O.S., Libik T.V., Pozdnyakova A.A., Satyukova L.Y. Precancerous lesions in structure of oral mucosa diseases (according to medical advisory data). Problemy stomatologii 2013; 2: 3-9.

6. Kois J.C., Truelove E. Detecting oral cancer: a new technique and case reports. Dent Today 2006; 25(10): 94-97.

7. Poh C.F., Zhang L., Anderson D.W., Durham J.S., Williams P.M., Priddy R.W., Berean K.W., Ng S., Tseng O.L., MacAulay C., Rosin M.P. Fluorescence visualization detection of field alterations in tumor margins of oral cancer patients. Clin Cancer Res 2006; 12(22): 6716-6722, https://doi. org/10.1158/1078-0432.ccr-06-1317.

8. Dyatel A.V. Povyshenie effektivnosti diagnostiki $i$ lecheniya zabolevaniy krasnoy kaymy gub u patsientov $s$ atopicheskim dermatitom. Dis. ... kand. med. nauk [Enhancement of diagnostic and treatment efficiency of vermilion border in patients with atopic dermatitis. $\mathrm{PhD}$ Thesis]. Nizhny Novgorod; 2015.

9. Oreshaka O.V., Dement'eva E.A. Some aspects of combination treatment of oral homogenous leukoplakia. Maestro stomatologii 2012: 1: 72-74. 